\title{
Oral Health and Feto-Maternal Outcomes in the Context of Sustainable Development Goals
}

\author{
Sunali Khanna* \\ Member National Academy of Medical Sciences, India
}

Submission: May 24, 2018; Published: July 09, 2018

"Corresponding author: Sunali Khanna, Member National Academy of Medical Sciences, India, Email: sunalikhanna@gmail.com

\begin{abstract}
The health-related goal of Sustainable Development Goals (SDGs) focuses on holistic health of all at all ages. Oral cavity acts as a route of entry for various microorganisms into the body and oral lesions are easily detectable. Thus, early intervention is possible and morbidity in the vulnerable populations can be reduced to a great extent.The association of maternal oral health and its implications on the child's health largely impacts the holistic health.Moreover, maternal and child health have been regarded as yardsticks of development in all civil societies. As oral health is an integral part of the overall health, it warrants to be investigated in an important stage of life such as pregnancy.In the public health scenario such vulnerable populations add up to the burden of the society due to lack of health care resources or inability to afford health care services. Thus, marginalizing oral health continues to pose a challenge in the public health scenario globally and especially in developing countries. Thus, to achieve the SDGs, developing health care policies to reduce health disparity and making oral health care accessible at grass roots level is justified.
\end{abstract}

Keywords: Oral health; Maternal health; Sustainable development goals

\section{Introduction}

The Sustainable Development Goals (SDGs) became official on the 1st of January 2016 and the deadline set for their achievement is 2030. The health goal is framed to fit broad terms that are relevant to all countries and all populations. They are intended to be inclusive of all populations, with economic, social and environmental sustainable development being the core focus.Health holds a central place in the Sustainable Development Goal (SDG) No.3 that is "To ensure healthy lives and promoting wellbeing for all at all ages." As there cannot be health without oral health; it becomes an integral part of SDGs.

The implications of poor oral health during the vulnerable state of pregnancy are known to dental surgeons and gynaecologists. Despite the awareness no rule of the thumb is prescribed for the management of women suffering from the oral conditions. Previous surveys suggest that almost $85 \%$ gynaecologists are aware of the consequences of periodontal disease on the outcome of pregnancy but still the rate of referral remains low for oral health screening [1,2].

Globally various steps have been taken to reduce the disparities and establish health equalities amongst populations. However, the vulnerable populations such as women and children persist to suffer due to lack of resources. Childbirth continues to take a toll on a large number of females and is a prime reason for increased mortality in this population [3]. It is known that Millennial Development Goals have paved the way for SDGs in 2016, however it is startling to know that the impact of oral health, direct or indirect, on one's lifestyle is not considered even in the SDGs [4]. Thus, there is a need to contemplate on how we can integrate oral health promotion and care with other sectors that influence health by using the common risk factor approach [5]. It is essential for the health-related global agendas to widen in order to emphasise on oral health issues.

The oral cavity is not an exception when the body undergoes various physiological changes. Increased/altered hormonal secretion and foetal growth induce several systemic changes which collectively make dental treatment challenging than routine treatment [4]. Also, procedures that can be done are at times questionable and hence the apprehension amongst pregnant patients and dentists needs to be addressed. Unfortunately, even the wide range of pain killers available is at times insufficient to cure certain types of pain leading to inability to control pain and thus causing the patients to suffer. Pain relief has acquired the status of a human right at a global level in order to overcome 
the hurdles against effective pain control. Health professionals encounter these problems on a daily basis and must have the knowledge regarding pain control to ensure efficient and safe pain treatment [6]. Moreover women should be assured about the safety of analgesics and risks of treating versus not treating pain during pregnancy and lactation [7].

\section{Oral Health in Pregnancy}

Gingivitis, gingival hyperplasia, pyogenic granuloma, salivary alterations are some of the common mucosal conditions occurring in pregnancy [8]. Erosion and dental caries are not uncommon and affect the hard tissue. They occur particularly due to increase in the acidic environment of oral cavity as a result of decrease in salivary $\mathrm{pH}$, severe vomiting, dietary changes [9]. Melasma, appearing as bilateral brown patches in the midfaceare seen in above $70 \%$ of pregnant women.

\section{Periodontitis and Gingivitis}

Recent studies have associated periodontal disease with pregnancy. Oestrogen levels increase the capillary permeability, thus predisposing pregnant women to gingivitis and gingival hyperplasia. According to American Academy of Periodontology, above 50\% women experience pregnancy gingivitis characterized by bleeding and swollen gums [10]. Pregnancy gingivitis is the inflammation of gums caused by plaque accumulation and reduced host response. Periodontitis is an inflammatory condition involving both the gingiva and the alveolar bone that is worsened during pregnancy. Gram negative anaerobic organisms produce various chemical mediators such as interleukins, prostaglandins and tumour necrotic factor which are responsible for destruction of periodontal tissue. Various studies on the alteration in salivary $\mathrm{pH}$ have proven that the salivary $\mathrm{pH}$ reduces progressively till the third trimester[11]. As a result there is increased caries incidence as well as a rise in mucosal lesions with over $44 \%$ pregnant women suffering from them[11].

Most of the studies have highlighted preterm/low birth weight as the consequence of pregnancy[10]. Studies have suggested a substantial association of periodontitis and preeclampsia in non-smokers[10]. The infected periodontal tissues may be associated with prematurity by acting as reservoirs of bacteria and their products, which can disseminate to the foetusplacenta unit. Furthermore, immunological mediators at high concentrations produced locally at the infected gingival tissues or systemically can reach the foetus-placenta unit, resulting in prematurity and low weight at birth. Although some aspects of the association between periodontitis and complications in pregnancy were elucidated, this relationship needs to be better studied and characterized.

\section{Caries Burden}

Caries is considered as an irreversible microbial disease affecting the hard tissues which leads to cavitation causing sensitivity and pain. Delaying the treatment of dentinal caries in the first or third trimester can have serious effects as dentinal caries may progress to pulpitis. Space infection, pulp necrosis, dentoalveolar abscesses are some of the consequences of untreated pulpitis. Hence to avoid/ restrict these, prompt treatment of caries is necessary.

Post-natal transmission of caries causing bacteria such as streptococcus mutans from mother to child occurs through common practices such as sharing of spoons, contaminated pacifiers and even kissing the child. The capacity of the child to harbour these bacteria depends on the diet, oral hygiene practices and fluoride exposure [12]. A recent study by Shearer et al attempts to correlate maternal oral health with caries experience in adulthood of the child [12].

\section{Dental Erosion}

Dental erosion is classified based on its cause as intrinsic and extrinsic. Extrinsic factors are acidic fruits, aerated drinks etc. Increase in the intra-abdominal pressure during pregnancy may result in an increased reflux. Dental erosion is rare unless vomiting is chronic, as in the case of hyperemesis gravidarum.

\section{Pyogenic Granuloma}

Pyogenic granuloma also known as pregnancy tumour is a nonspecific growth that occurs frequently in pregnant women. The treatment plan depends on its severity of interference with normal function. Conservative management such as plaque control is preferred over surgical methods. However, surgical removal in case of hindrance to mastication or continuous trauma to the growth helps to curb secondary infection [13]. Even though recurrence is often seen, the lesion subsides by itself post pregnancy.

\section{Temporomandibular Disorders (TMDs)}

Temporomandibular joint (TMJ) problems significantly cause discomfort and affect activities of daily living. It has shown serious effects on patients such as sleep disturbances, irritability, reduced physical activity, anxiety and depression[14]. During pregnancy certain factors such as sleep disruption, morning sickness, and increased relaxin secretion contribute to temporomandibular joint disorders (TMDs). Other important factors such as impaired occlusion and muscle function are other causative factors. Studies in the past have also revealed a correlation between TMDs and Vitamin D levels[15]. Vitamin D insufficiency as well as deficiency is higher in females due to social customs that restrict women from being exposed to direct sunlight[16]. Even though it is considered to be a self- limiting disorder certain measures can be helpful to reduce the suffering. Avoiding certain food items and particular habits that induce TMD can curtail the impact of TMD to an extent. Appliances such as oral appliance or bite plate have a cushioning effect on the TMJ and relieve the jaw muscles. Night guards, exercises for jaw muscles and some relaxation methods have shown to improve TMDs [14]. 


\section{Safeth of Analgesics}

They are the primary medicines used to treat various types of pain. Ineffective pain control disturbs the patient physically as well as mentally. Thus, prescribing adequate but safe drug dose is necessary. Traditionally paracetamol is considered to be the safest of all the analgesics due to its least side effects. NSAIDs are avoided as they are inhibitors of cyclooxygenase and cause premature closure of ductusarteriosus and pulmonary resistance vessels[17]. Opioids such as Codeine are commonly found in over the counter drugs. Other alternatives are considered before opting for opioids[7].

Most of the analgesics are compatible during lactation period[18]. Fortunately, the commonly used drugs in dentistry are safe in pregnancy. Nevertheless, dentists must evaluate carefully the risks versus benefits of prescribing or administering any drug to a pregnant patient. As always it is important to note that if a patient with pain or infection, the first line of treatment should be removal of its source. If pharmacotherapy is initiated, prescribing the lowest dose for the shortest duration is ideal.

\section{Conclusion}

Neglect toward the oral health conditions during pregnancy have a synergistic effect with the hormonal fluctuations and dietary changes contributing to compromised oral hygiene. Thus, the effect of oral hygiene of the mother and its consequences on the overall health of the child is of utmost importance. Therefore, it is warranted that oral health policies be oriented towards developing sustainable, priority driven programmes that primarily reduce the health disparities [5].

For mankind to utilize the vast expanse of natural resources and sustain it over a long period, it is imperative for professionals to work towards the successful realization of the SDGs. Therefore, engaging everyone becomes the key to fruitful implementation and actualization. Moreover, academic institutions need to advocate training of oral health professionals to develop an educational strategy towards SDG training and education.To achieve universal health coverage outcomes, it is important to improve geographical coverage of health services, higher coverage of skilled birth attendance and smaller rich-poor disparity. This in turn includes universal coverage of maternal and child health services. Addressing food security, malnutrition, environmental safety, universal health coverage and maternal and child health require multidimensional and multi-sectorial policy interventions.

\section{References}

1. Patil S, Thakur R, K M, Paul ST, Gadicherla P, et al. (2013) Oral Health Coalition: Knowledge, Attitude, Practice Behaviours among Gynaecologists and Dental Practitioners. J Int Oral Health 5(1): 8-15.

2. George A, Johnson M, Blinkhorn A, Ajwani S, Bhole S, et al. (2013) The oral health status, practices and knowledge of pregnant women in south-western Sydney. Aust Dent J 58(1): 26-33.

3. Marino R, Banga R. Un Sustainable Development Goals (SDGs): A time to act. Journal of Oral Research 5: 5-6.

4. Kurien S, Kattimani VS, Sriram RR, Sriram SK, Rao VKP, et al. (2013) Management of Pregnant Patient in Dentistry. J Int Oral Health 5(1): 88-97.

5. Hobdell M, Petersen P (2003) Global goals for oral health 2020. International Dental Journal 53: 285-288.

6. Cazacu I, Mogosan C, Loghin F (2015) Safety issues of current analgesics: an update. Clujul Med 88(2): 128-136.

7. Khanna S (2016) Safety of analgesics in pregnancy. International Journal of Obstetrics and Gynaecological Research 3(1): 208-212.

8. Khanna S, Malhotra S (2010) Pregnancy and Oral Health: Forgotten Territory Revisited. Journal of Obstetrics and Gynaecology India 60(2): 123-127.

9. Silk H, Douglass A, Douglass JM, Silk L (2008) Oral health during pregnancy. American Family Physician 77(8): 1139-1144.

10. Zi MYH, Longo PL, Bueno-Silva B, Mayer MPA (2014) Mechanisms Involved in the Association between Periodontitis and Complications in Pregnancy. Front Public Health 2: 290.

11. Jain K, Kaur H (20105) Prevalence of oral lesions and measurement of salivary $\mathrm{pH}$ in the different trimesters of pregnancy. Singapore Medical Journal 56(1): 53-57.

12. Shearer DM, Thomson WM, Broadbent JM, Poulton R (2011) Maternal Oral Health Predicts Their Children's Caries Experience in Adulthood. Journal of Dental Research 90(5): 672-677.

13. Nair V (1994) Oral pyogenic granuloma in pregnancy: a predicament. International Medical Journal 23: 64-65.

14. Khanna S, Parulekar N, Dhaimade P (2017) Influence of Vitamin D on the temporomandibular joint and the activities of daily living. Journal of Clinical \& Diagnostic Research 11(11): ZC 31-34.

15. Bayramova A (2018) TMD and pregnancy? Clinical Journal of Obstetrics and Gynecology 1: 001-006.

16. Khanna S, Parulekar N, Dhaimade PA, Gharpure AS (2017) Evaluation of serum Vitamin D: an institutional study in Mumbai. Journal of Nutrition and Health Sciences 4(3): 1-6.

17. Ouanounou A, Hass D (2016) Drug therapy during pregnancy: implications in dental practice. Br Dent J 220(8): 413-417.

18. Kennedy D (2011) Analgesics and pain relief in pregnancy and breastfeeding 34: 8-10. 


\section{Your next submission with Juniper Publishers} will reach you the below assets

- Quality Editorial service

- Swift Peer Review

- Reprints availability

- E-prints Service

- Manuscript Podcast for convenient understanding

- Global attainment for your research

- Manuscript accessibility in different formats

( Pdf, E-pub, Full Text, Audio)

- Unceasing customer service

Track the below URL for one-step submission https://juniperpublishers.com/online-submission.php 